\title{
Os Livros Didáticos de Química e a Resistência às Mudanças no Estilo de Pensamento
}

\section{The Chemistry Textbooks and the Resistance to Change the Style of Thinking}

\author{
Tiago Franceschini da Rosa ${ }^{\mathrm{a}}$; Marcelo Lambach ${ }^{\mathrm{a}}$ \\ a Universidade Tecnológica Federal do Paraná, Curitiba, Brasil - tfranceschini@ gmail.com, marcelolambach@utfpr.edu.br
}

Palavras-chave:

Livro didático. PNLD.

Estilo de pensamento.

Circulação de ideias.

Ensino de química.

\section{Keywords:}

Didactic textbook. PNLD.

Style of thinking.

Movement of ideas.

Chemistry for teaching.
Resumo: O presente artigo busca desenvolver uma reflexão de caráter epistemológico acerca do processo de seleção dos livros didáticos de Química, distribuídos trienalmente pelo Programa Nacional do Livro Didático. O objetivo foi revelar a existência de um padrão recorrente na escolha desses materiais. A pesquisa, de cunho exploratório, realizada com base nos dados fornecidos pelo Ministério da Educação, procurou confrontar o percentual de escolas atendidas com a quantidade de títulos escolhidos, bem como a descrição dos materiais com o parecer para cada obra disponibilizada nos processos de 2008 a 2015, visando com isso, demonstrar a existência de uma tendência para certo Estilo de Pensamento, do qual os professores estão vinculados e provavelmente fortalecido por diversos acoplamentos, passivos e ativos, ao longo da formação profissional. Isso demonstra que a escolha nem sempre busca atender às necessidades e realidades dos estudantes, mas às concepções de ensino presentes na prática de cada docente.

Abstract: This article aims to develop an epistemological reflection about the process for selection of the Chemistry textbooks distributed for the National Program of the Didactic Textbooks. The goal of this study was to demonstrate the existence of a pattern for the choice of this material. The research, of exploratory nature, checked the data supplied by Ministry of Education and confronted the percent of participating schools with the most chosen textbooks, the description of each book with the view for books provided for the process of 2008 to 2015 , aiming at revealing the existence of a tendency for maintenance of the style of thinking, to which teachers are bound and has already been strengthened for many couplings, strengthened through the professional formation. This shows that the choice does not always serve reality's needs of students, but to the concepts of teaching present in the practice for each teacher. 


\section{Introdução}

Desenvolver um ensino contextualizado e capaz de despertar o interesse dos estudantes é um dos principais propósitos dos docentes e dos documentos orientadores da área de Química. Porém, nem sempre é possível atingir tal objetivo, uma vez que, no contexto escolar existem aspectos que acabam dificultando esse processo, como por exemplo, a formação docente, as condições de trabalho, entre outras. Com isso, um caminho viável é buscar suporte nos materiais didáticos, em especial nos livros didáticos (LD) que são disponibilizados gratuitamente para alunos e professores da rede pública de ensino.

Segundo Nuñez (2003, p. 2), "o livro didático passou a ser o principal controlador do currículo", pois representa o suporte de maior utilização na hora de planejar e de ensinar. A vinculação do trabalho docente ao LD acontece de tal forma que esse material chega a determinar desde a organização dos planos de trabalho docente até as discussões, experimentos, atividades e contextualizações que serão realizadas durante as aulas.

Assim, considerando esse cenário, há que se entender melhor o processo para a seleção dos LD, para que se torne um ato consciente, de natureza social e política, fundamentado principalmente nas necessidades dos estudantes. Exige ainda, uma reflexão sobre o contexto sociocultural da comunidade escolar, o perfil dos alunos que utilizarão esse material, os aspectos científicos, tecnológicos e históricos do momento em que o livro será adotado, bem como o encaminhamento dado pelo autor na abordagem dos conteúdos curriculares (NUÑEZ, 2003).

Por isso, o objetivo deste artigo é identificar, por meio da análise dos dados fornecidos pelo Ministério da Educação (MEC) (BRASIL, 2008; 2011; 2014), junto ao Fundo Nacional de Desenvolvimento da Educação (FNDE), o que os professores de Química levam em consideração na hora de selecionar uma obra do $\mathrm{PNLD}_{\mathrm{EM}}{ }^{1}$ para sua escola. Para isso, tomou-se como referência a epistemologia de Ludwik Fleck (2010), com a qual se elenca os possíveis motivos que levaram os professores a optarem por uma mesma obra e/ou autor repetidas vezes ao longo do tempo, mesmo que tal escolha leve a uma compreensão de ensino distinta daqueles propósitos apontados logo no início desta seção.

Ao adotar esse referencial analítico, quis-se compreender e localizar pontos para subsidiar e justificar a predileção por determinadas obras na hora da seleção do LD. Assim, aventa-se a possibilidade de promover complicações nos prováveis Estilos de Pensamento (EP) para com isso, estimular a reflexão e a adoção de novas concepções mediante a escolha dos materiais didáticos.

\footnotetext{
${ }^{1}$ PNLD/EM: Incorporação das siglas PNLEM (2008) e PNLD (2012; 2015), uma vez que o artigo faz referência às obras participantes de ambos os programas.
} 
O presente estudo tomou como base os dados disponibilizados no site do MEC, em que consta a relação dos LD de Química aprovados pelo PNLD/EM para todo o território nacional. Optou-se por verificar as edições de 2008 a 2015, pois nesse período o programa já possuía uma identidade própria e consolidada, implicando em pequenas mudanças na distribuição de autores e nas obras disponibilizadas para a seleção. Cabe destacar que essa análise realizada nos livros didáticos de Química teve a finalidade de indicar o padrão de escolha dos títulos, como ele varia no decorrer dos anos e se possui relação com o valor/estrutura das obras.

\section{A importância da Alfabetização Científica e Tecnológica no Ensino de Química}

Segundo Sasseron e Carvalho (2011), o termo alfabetização científica foi primeiramente utilizado na língua inglesa, ao que tudo indica, pelo pesquisador em educação Paul Hurd, no ano de 1958, na obra intitulada Scientific Literacy: Its Meaning for American Schools. Foi a partir desse trabalho que esse termo adquiriu destaque na área pedagógica, fazendo com que fosse traduzido, utilizado e discutido no âmbito acadêmico de diversas nacionalidades, ganhando proporções e definições cada vez mais especializadas (CARVALHO; SASSERON, 2011).

Com a vasta utilização desse termo, muitos pesquisadores passaram a questionar seu significado em relação a sua tradução estrita. Inicialmente, utilizava-se o termo "Letramento Científico", mas logo ele se mostrou inadequado, uma vez que fazia referência ao domínio dos códigos específicos da ciência, ou seja, o letramento se daria quando o estudante adquirisse e replicasse um conjunto de concepções, definições prévias, signos e símbolos científicos.

Por isso, muitos trabalhos passaram a adotar a expressão Alfabetização Científica e Tecnológica (ACT), pois o próprio livro de Hurd (1958), assim como outros artigos e obras lançadas sequencialmente, viam a Scientific Literacy como uma compreensão mais abrangente, prática e bem engajada com aspectos sociais, críticos e até participativos de um estudante que se prepara para viver a cidadania. Deriva daí a aproximação que muitos autores fazem ao pensamento de Paulo Freire (2000, p. 118), quando ele diz que "a alfabetização é mais que o simples domínio psicológico e mecânico de técnicas de escrever e de ler. É o domínio destas técnicas em termos conscientes.”

Neste estudo, adotar-se-á a compreensão aproximada à Freire (2000), entendendo que tal abordagem está voltada à formação conscientizadora e à incorporação de saberes na prática sociocultural, pois assim os sujeitos estarão preparados e poderão agir sobre a realidade vivida com base em concepções científicas. 
Nesse sentido, espera-se que o conhecimento científico-escolar propiciado por esse enfoque de ensino, possa auxiliar os estudantes a examinarem e participarem de temas importantes à sociedade, contribuindo para o desenvolvimento da comunidade em que estão inseridos, obtendo mais qualidade de vida e habilidade intelectual (LORENZETTI, 2000).

\section{As contribuições dos livros didáticos no processo de Alfabetização Científica e}

\section{Tecnológica}

Atualmente, a revisão e aceitação dos LD, que participam dos editais do PNLD/EM, está a cargo do MEC e da FNDE, cuja principal filosofia e critério de escolha é que os materiais forneçam subsídios literários para alunos e professores da rede pública de ensino. A partir dessa iniciativa, busca-se melhorar a qualidade de ensino e suprir as necessidades de uma aprendizagem contextualizada e concomitante às premências de formação crítica e reflexiva de estudantes participativos da comunidade em que vivem (NUÑEZ, 2003).

Por isso, depreende-se que o livro didático possa auxiliar o professor na busca por opções didático-metodológicas eficientes para a promoção de ACT, uma vez que suas estruturas são frequentemente reformuladas e estão acordadas com as normas do PNLD. Devido a isso, é de se esperar que o LD apresente abordagens cada vez mais contextualizadas com a vivência e as experiências diárias dos educandos, e com isso, relações entre os conteúdos, as tecnologias e suas finalidades sociais.

Pautado nessas condicionantes, o LD, dependendo de como seja concebido e estruturado, pode ser utilizado com o propósito de auxiliar no planejamento e na elaboração de temas para as aulas, além de fomentar discussões, observações e reflexões na turma, despertando a curiosidade, tanto de alunos quanto de professores, para a extensão da pesquisa e para possíveis empregos da Ciência na escola e na vida (BRASIL, 2014).

Muito embora o uso do material selecionado e distribuído pelo PNLD não seja uma novidade, ele se mostra "como uma possibilidade bastante promissora para a aprendizagem de Química no Ensino Médio” (BRASIL, 2014, p. 10). Em contrapartida, a Unesco (2005), em seu documento intitulado "Ensino de Ciências: O Futuro em Risco", traz um importante contraponto, ao afirmar que

[...] na escola brasileira, o ensino de Ciências tem sido tradicionalmente livresco e descontextualizado, levando o aluno a decorar, sem compreender os conceitos e a aplicabilidade do que é estudado. Assim, as Ciências experimentais são desenvolvidas sem relação com as experiências [...]. Em outras palavras, as escolas não estão preparadas para promover um ambiente estimulante de educação científica e tecnológica (UNESCO, 2005, p. 3).

Nessa perspectiva, tem-se de um lado as expectativas do PNLD/EM, que visam distribuir materiais para auxiliar os professores e os estudantes no processo de ensinoaprendizagem e, de outro, a pouca criticidade no processo de escolha, associada à falta de 
momentos de reflexão para delimitar qual obra melhor atenderia às necessidades do professor e dos alunos. Some-se a isso as limitações impostas pelas condições de trabalho e pela formação docente, o que se pode esperar é um uso mais ou menos adequado do LD.

Tal como destaca Nuñez (2003, p.3), “os professores devem ter um domínio de saberes diversos a serem mobilizados para assumir a responsabilidade ética de saber selecionar os livros didáticos, e não só isso, como também, estar capacitados para avaliar as possibilidades e limitações dos livros recomendados pelo MEC".

\section{Análise das obras participantes do PNLD/EM de Química nos anos de 2008 a 2015}

Com o intuito de compreender as influências sobre o processo de escolha das obras do PNLD/EM, foram elaboradas três tabelas que trarão a relação de livros, valores e quantidade de obras escolhidas nas diversas regiões e estados brasileiros.

Tabela 1 - Dados estatísticos do FNDE sobre o programa PNLEM de 2008

\begin{tabular}{|c|c|c|}
\hline Referência da obra participante & $\begin{array}{l}\text { Valor }(\mathbf{R} \$) \text { médio } \\
\text { do volume }\end{array}$ & $\begin{array}{l}\text { Quantidade } \\
\text { escolhida }\end{array}$ \\
\hline $\begin{array}{l}\text { FELTRE, R. Química. 6. ed. São Paulo: Moderna, } \\
\text { 2005. v. 1, 2, } 3 \text {. }\end{array}$ & 9,25 & 731.304 \\
\hline $\begin{array}{l}\text { CANTO, E. L.; PERUZZO, F. M. Química na } \\
\text { abordagem do cotidiano. 3. ed. São Paulo: } \\
\text { Moderna, 2005. v. } 1,2,3 .\end{array}$ & 7,13 & 354.803 \\
\hline $\begin{array}{l}\text { NOBREGA, O. S.; SILVA, E. R.; SILVA, R. H. } \\
\text { Química. 1. ed. São Paulo: Ática, 2005. v. único. } \\
\text { BIANCHI, J. C. A.; ALBRECHT, C. H.; MAIA, J. }\end{array}$ & 12,83 & 174.603 \\
\hline $\begin{array}{l}\text { Universo da Química. 1. ed. São Paulo: FTD, } 2005 . \\
\text { v. único. }\end{array}$ & 14,35 & 119.551 \\
\hline $\begin{array}{l}\text { SANTOS, W. L. P.; MÓL, G. S. (Coords). Química } \\
\text { e Sociedade. 1. ed. São Paulo: Nova Geração, } 2005 . \\
\text { v. único. }\end{array}$ & 29,50 & 116.931 \\
\hline $\begin{array}{l}\text { MORTIMER, E. F.; MACHADO, A. H. Química. } 1 . \\
\text { ed. São Paulo: Scipione, 2005. v. único. }\end{array}$ & 12,51 & 83.726 \\
\hline
\end{tabular}

Fonte: Brasil (2017).

Tabela 2 - Dados estatísticos do FNDE sobre o programa PNLD de 2012

\begin{tabular}{|c|c|c|}
\hline Referência da obra participante & $\begin{array}{l}\text { Valor (R\$) médio } \\
\text { do volume }\end{array}$ & $\begin{array}{l}\text { Quantidade } \\
\text { escolhida }\end{array}$ \\
\hline $\begin{array}{l}\text { CANTO, E. L.; PERUZZO, F. M. Química na } \\
\text { abordagem do cotidiano. } 4 . \text { ed. São Paulo: } \\
\text { Moderna, 2006. v. } 1,2,3 .\end{array}$ & 8,08 & 4.901 .698 \\
\hline $\begin{array}{l}\text { REIS, M. Química: Meio ambiente, Cidadania e } \\
\text { Tecnologia. 1. ed. São Paulo: FTD, 2010. v. 1, 2, } 3 \text {. }\end{array}$ & 8,95 & 1.777 .922 \\
\hline $\begin{array}{l}\text { LISBOA, J. C. F. (Org). Ser protagonista: Química. } \\
\text { 1. ed. São Paulo: SM, 2010. v. 1, } 2,3 \text {. }\end{array}$ & 11,37 & 1.425 .109 \\
\hline $\begin{array}{l}\text { MORTIMER, E. F.; MACHADO, A. H. Química. } 1 . \\
\text { Ed. São Paulo: Scipione, 2011. v. 1, 2, } 3 .\end{array}$ & 6,41 & 775.234 \\
\hline $\begin{array}{l}\text { SANTOS, W. L. P.; MÓL, G. S. (Coords.). Química } \\
\text { Cidadã. 1. ed. São Paulo: Nova Geração, 2011. v. 1, } \\
2,3 \text {. }\end{array}$ & 14,47 & 593.373 \\
\hline
\end{tabular}

Fonte: Brasil (2017). 
Tabela 3 - Dados estatísticos do FNDE sobre o programa PNLD de 2015

\begin{tabular}{lcc}
\hline $\begin{array}{l}\text { Referência da obra participante } \\
\text { REIS, M. Química. 1. ed. São Paulo: Ática, 2013. v. }\end{array}$ & $\begin{array}{c}\text { Valor (R\$) médio } \\
\text { do volume }\end{array}$ & $\begin{array}{c}\text { Quantidade } \\
\text { escolhida }\end{array}$ \\
$\begin{array}{l}\text { 1, 2, 3. } \\
\text { ANTUNES, M. T. (Org). Ser protagonista: }\end{array}$ & 7,77 & 3.032 .749 \\
$\begin{array}{l}\text { Química. 2. Ed. São Paulo: SM, 2013. v. 1, 2, 3. } \\
\text { SANTOS, W. L. P.; MÓL, G. S. (Coords.). Química }\end{array}$ & & \\
$\begin{array}{l}\text { Cidadã. 2. ed. São Paulo: AJS, 2013. v. 1, 2, 3. } \\
\text { MORTIMER, E. F.; MACHADO, A. H. Química. 2. }\end{array}$ & 8,55 & 1.572 .985 \\
\begin{tabular}{l} 
ed. São Paulo: Scipione, 2013. v. 1, 2, 3. v. 1, 2, 3. \\
\hline
\end{tabular}
\end{tabular}

Fonte: Brasil (2017).

\section{A relação entre o valor de venda da obra e sua seleção pelos professores}

Uma primeira análise dos dados apresentados nos permite identificar que o valor médio das obras não é, necessariamente, um fator determinante para a escolha, uma vez que o livro com menor valor nem sempre tem sido o mais enviado às escolas. Diferentemente do que se pode esperar a partir de uma compreensão economicista, a qual, devido ao fato de cada instituição indicar duas dentre as 4 ou 5 obras apresentadas, o programa poderia enviar, nesse caso, aquela de menor valor, prezando pela redução de custos em detrimento da escolha principal do professor.

A partir dessa primeira análise, é possível inferir que os livros de Machado e Mortirmer e os de Santos e Mól foram os que obtiveram menor adesão nesses três anos de edições PNLD analisadas; porém, são os únicos que participaram de todos os anos da escolha. Isso parece indicar, pelo lado dos autores - pesquisadores consagrados na área de ensino de Química -, a persistência em disseminar, ou promover uma circulação intercoletiva, nos termos de Fleck (2010), das compreensões do que seja o ensino de Química em uma determinada concepção pedagógica e metodológica. Pelo lado dos professores do Ensino Médio, a baixa adesão pode ser relativa à limitada compreensão das concepções pedagógicas e metodológicas que fundamentam o LD, cuja confecção foi organizada ou coordenada por eles.

Na perspectiva de Fleck (2010), esse resultado, referente aos livros de Machado e Mortirmer e de Santos e Mól, pode representar a vinculação da escolha de uma práxis docente orientada por certos referenciais e por uma cultura pedagógica convencional, sendo esses, indícios de um Estilo de Pensamento, tal como aponta Lambach $(2007 ; 2013)$.

Além disso, esse resultado quantitativo, quando mirado pelo viés das atribuições da Comissão Nacional do Livro Didático - responsável por examinar os materiais apresentados ao programa e proferir um julgamento referente à autorização de seu uso -, remete à 
conclusão de que, embora pouco escolhidos pelos professores, são os LD que conseguiram manter um padrão relativo à qualidade, desde o ano de 2008 (BRASIL, 1938).

\section{Adequações da obra às demandas dos editais de seleção}

Outro aspecto relevante diz respeito às adequações ocorridas no decorrer das edições do programa, tanto com relação ao número/volume dos livros disponíveis para a seleção, quanto ao atendimento de instituições de ensino.

Primeiramente, a comparação das opções de obras participantes entre a tabela 1 e a tabela 3 possibilita constatar que, no início, os volumes estavam distribuídos em duas opções, únicos ou fragmentados (vários volumes), direcionando à escolha não somente pelo conteúdo da obra, mas também pela necessidade de seu uso. Isso pois, uma escola que tenha preferência/necessidade de obras com volume único, conforme a tabela 1, estaria restrita à escolha entre três títulos, sendo que esse padrão se desfez no decorrer das edições, ampliando a acessibilidade das escolas em relação à diversidade de obras ofertadas.

O segundo fator está relacionado ao aumento da quantidade de escolas atendidas pelo programa ao longo do tempo, o que pode indicar, concomitantemente, um aumento no prestígio, na divulgação e na acessibilidade do programa.

Percebe-se que há um crescimento no montante de livros distribuídos às escolas do Ensino Médio, sendo que no ano de 2015 (tabela 3) houve aproximadamente 20\% a mais de circulação em relação ao ano de 2008 (tabela 1) (BRASIL, 2017).

Outro dado que requer atenção é a concentração das escolhas por determinadas obras. Por exemplo, quando se observa a distribuição do percentual de indicações nos livros didáticos oferecidos em 2008 (tabela 1), percebe-se que praticamente 50\% delas estão concentradas em apenas um dos materiais. Para analisar e discutir sobre esse padrão, é necessário, primeiramente, focar a atenção no conteúdo estruturante de cada material.

\section{Os conteúdos estruturantes dos livros didáticos no PNLD/EM de 2008 a 2015}

A seguir será apresentado um quadro comparativo das estruturas gerais de cada obra disponibilizada nos programas de 2008, 2012 e 2015. As descrições de cada obra foram sintetizadas do parecer técnico disponível no Guia do Livro Didático e indicam a estrutura de cada material, a abordagem dos conteúdos, o uso de temas e contextualizações, os aspectos pedagógico-metodológicos e o foco de aprendizagem.

Sobre o preenchimento desse quadro, quando uma obra de determinado autor participou de várias edições do PNLD/EM, optou-se por utilizar o parecer técnico mais recente do material. Essa escolha foi adotada, pois, quando se considera a ficha de cada material nos três manuais $(2008,2012$ e 2015), fica claro que os autores sustentam a mesma estruturação didática de conteúdos, sendo encontradas mudanças apenas nos tópicos como 
foco de questões, revisão de vestibulares, textos de contextualização e guia para experiências em sala (BRASIL, 2017).

Quadro 1 - Comparativo entre a estrutura das principais obras do PNLD/EM de 2008 a 2015

\begin{tabular}{|c|c|}
\hline Referência & Descrição da estrutura da obra \\
\hline $\begin{array}{l}\text { FELTRE, R. } \\
\text { Química. 6. ed. São } \\
\text { Paulo: Moderna, } \\
\text { 2005. v. único. }\end{array}$ & $\begin{array}{l}\text { Os LD possuem apresentação, sumário, sequência de capítulos, lista de } \\
\text { siglas, sugestão de leitura, exercício de revisão, atividade prática, exercícios } \\
\text { complementares. } \\
\text { A abordagem dos conteúdos acontece principalmente por meio de leituras, } \\
\text { pesquisas e atividades práticas. } \\
\text { A contextualização dos conteúdos ocorre de forma implícita nos textos de } \\
\text { cada capítulo. } \\
\text { O parecer técnico diz que esse LD explora os assuntos da Química por meio } \\
\text { de textos descritivos e questionários. Com relação aos aspectos pedagógico- } \\
\text { metodológicos, a obra tenta despertar o interesse pelo caráter prático e } \\
\text { aplicado dos conteúdos, além de valorizar a leitura e a resolução de } \\
\text { exercícios (BRASIL, 2008). }\end{array}$ \\
\hline $\begin{array}{l}\text { CANTO, E. L.; } \\
\text { PERUZZO, F. M. } \\
\text { Química na } \\
\text { abordagem do } \\
\text { cotidiano. 4. ed. São } \\
\text { Paulo: Moderna, } \\
\text { 2006. v. } 1,2,3 \text {. }\end{array}$ & $\begin{array}{l}\text { Os três volumes do LD possuem como estrutura padrão figuras iniciais que } \\
\text { buscam estimular o levantamento de ideias prévias e reflexões dos alunos. } \\
\text { Sequencialmente, há a apresentação dos conteúdos e são oferecidos um } \\
\text { conjunto de exercícios, leituras para a conexão com o cotidiano, exercícios } \\
\text { de fixação e mapa mental do capítulo. } \\
\text { A abordagem dos conteúdos acontece principalmente de forma a dar ênfase } \\
\text { para regras, teorias, nomenclaturas e resolução de exercícios. } \\
\text { A contextualização com temáticas sociais, tecnológicas e ambientais } \\
\text { acontece no início de cada capítulo, com a questão "o que você pensa a } \\
\text { respeito?". } \\
\text { O parecer técnico diz que esse LD explora os assuntos da Química por meio } \\
\text { de textos descritivos e questões norteadoras. Com relação aos aspectos } \\
\text { pedagógico-metodológicos, a obra principalmente estimula a discussão de } \\
\text { sala de aula sobre temas de interesse dos estudantes (BRASIL, 2011). }\end{array}$ \\
\hline $\begin{array}{l}\text { REIS, M. Química. } \\
\text { 1. ed. São Paulo: } \\
\text { Ática, 2013. v. 1, 2, } \\
\text { 3. }\end{array}$ & $\begin{array}{l}\text { Os LD apresentam, na abertura de cada capítulo, um tema relacionado a } \\
\text { questões ambientais e sociais, a partir do qual se propõe assuntos-chave } \\
\text { para depois destrinchar os conceitos químicos. } \\
\text { A abordagem dos conteúdos pretende superar visões do ensino de Química, } \\
\text { baseadas exclusivamente em regras e nomenclaturas. } \\
\text { A contextualização com temáticas sociais, tecnológicas e ambientais } \\
\text { acontece exclusivamente na abertura e encerramento de cada capítulo. } \\
\text { O parecer técnico diz que esse LD explora os assuntos da Química por meio } \\
\text { de conhecimentos do senso comum. Com relação aos aspectos pedagógico- } \\
\text { metodológicos, a obra favorece a problematização de informações do } \\
\text { cotidiano com a linguagem química por meio de textos e exercícios } \\
\text { (BRASIL, 2014). }\end{array}$ \\
\hline $\begin{array}{l}\text { MORTIMER, E. F.; } \\
\text { MACHADO, A. H. } \\
\text { Química. 2. ed. São } \\
\text { Paulo: Scipione, } \\
\text { 2013. v. 1, 2, 3. }\end{array}$ & $\begin{array}{l}\text { Os LD dessa coleção estruturam a abertura de cada capítulo com uma } \\
\text { atividade reflexiva, o desenvolvimento de um projeto e um texto científico- } \\
\text { investigativo. As sessões de atividades incluem experimentos, exercícios e } \\
\text { estudos dirigidos. } \\
\text { A abordagem dos conteúdos acontece principalmente de forma temática, } \\
\text { interdisciplinar e experimental. } \\
\text { A contextualização com temáticas sociais, tecnológicas e ambientais } \\
\text { acontece de forma prioritária e em todos os momentos, resgatando, de forma } \\
\text { paralela, os conteúdos que estejam associados a elas. } \\
\text { O parecer técnico diz que esse LD explora os assuntos da Química por meio } \\
\text { de projetos, experimentos e contextualizações. Com relação aos aspectos } \\
\text { pedagógico-metodológicos, a obra favorece a construção de situações- } \\
\text { problema, valorizando a autonomia e o pensamento crítico (BRASIL, } \\
\text { 2014). }\end{array}$ \\
\hline
\end{tabular}




\begin{tabular}{|c|c|}
\hline $\begin{array}{l}\text { SANTOS, W. L. P.; } \\
\text { MÓL, G. S. } \\
\text { (Coords.). Química } \\
\text { Cidadã. 2. ed. São } \\
\text { Paulo: AJS, 2013. v. } \\
1,2,3 .\end{array}$ & $\begin{array}{l}\text { Os três volumes do LD apresentam, no início de cada capítulo, um "Tema } \\
\text { em foco", com questões geradoras de discussão, seguido de momento de } \\
\text { reflexão, textos interdisciplinares sociocientíficos e atividades. } \\
\text { A abordagem dos conteúdos acontece de acordo com a perspectiva sócio- } \\
\text { histórica, valorizando a reflexão e o diálogo em sala de aula. } \\
\text { A contextualização com temáticas sociais, tecnológicas e ambientais é o } \\
\text { eixo central dessa obra. } \\
\text { O parecer técnico diz que esse LD explora os assuntos da Química por meio } \\
\text { de ações cidadãs e atitudes sustentáveis. Com relação aos aspectos } \\
\text { pedagógico-metodológicos, a obra propõe que o professor assuma um papel } \\
\text { de mediador e favoreça a formação consciente de um estudante crítico e } \\
\text { participativo (BRASIL, 2014). }\end{array}$ \\
\hline $\begin{array}{l}\text { ANTUNES, M. T. } \\
\text { (Org). Ser } \\
\text { Protagonista: } \\
\text { Química. 2. ed. São } \\
\text { Paulo: SM, 2013. v. } \\
1,2,3 .\end{array}$ & $\begin{array}{l}\text { Os LD apresentam, ao longo dos capítulos, questões para reflexão, textos } \\
\text { com imagens que relacionam o conteúdo ao cotidiano, exercícios e artigos } \\
\text { científicos para análise e discussão. } \\
\text { A abordagem dos conteúdos acontece de forma articulada entre o contexto } \\
\text { sociocultural, a história e a experimentação. } \\
\text { A contextualização com temáticas sociais, tecnológicas e ambientais } \\
\text { acontece em forma de texto e ao final de cada capítulo. } \\
\text { O parecer técnico diz que esse LD explora os assuntos da Química por meio } \\
\text { de exemplos do cotidiano, imagens, experimentos e exercícios. Com relação } \\
\text { aos aspectos pedagógico-metodológicos, a obra sugere a leitura e a } \\
\text { discussão e a experimentação a partir dos temas sugeridos em cada capítulo } \\
\text { (BRASIL, 2014). }\end{array}$ \\
\hline
\end{tabular}

Fonte: Brasil (2008; 2011; 2014).

\section{A relação entre a estrutura de conteúdos e o padrão de escolha do livro didático}

Retomando o último ponto de discussão, o qual se constatou que, no ano de 2008, $46 \%$ das escolas escolheram o material produzido por R. Feltre, agora pode-se ampliar o foco de observação. Segundo a descrição do Guia do Livro Didático (2008), trata-se de uma obra com ampla perspectiva na descrição das diversas teorias científicas, na sequência linear e progressiva da apresentação dos conteúdos curriculares (forma convencional) e estruturada basicamente por textos descritivos, sugestões de experiências e listas de exercícios.

Já os livros produzidos por Mortimer e Machado apresentaram um dos menores percentuais de escolha, sendo de 5\% em 2008, 8\% em 2012 e 7\% em 2015. Ao se contrapor essa proporção de escolha com o parecer técnico, percebe-se que os autores dessas obras optaram por não seguir a ordem convencional dos conteúdos básicos para o Ensino Médio, além de que, apresentaram foco principal na contextualização de temas cotidianos, trazendo seu conteúdo científico embutido na discussão desses assuntos. O LD faz sugestão ao uso de projetos, experimentos, usos e aplicações tecnológicas, discussões em sala e listas de exercícios.

Seguindo a mesma orientação, a obra coordenada por Santos e Mól também apresentou uma baixa adesão de escolha (7\% em 2008, 6\% em 2012 e 21\% em 2015); porém, menor do que aquela obtida por Mortimer e Machado. Esse material apresenta um grande enfoque social, científico e tecnológico, buscando contextos e situações cotidianas para confrontar teorias científicas e conhecimentos específicos da Química, como também preza 
pela forma convencional de apresentar os conteúdos e traz sugestões de atividades, experimentos, projetos e listas de exercícios.

Com a ausência do livro do Feltre no ano de 2012, a preferência se deslocou para a obra de Canto e Peruzzo. Pode-se observar uma semelhança entre os pareceres dos dois materiais. Ambos optam pela sequência convencional de abordagem dos conteúdos, descrições textuais e listas de exercícios. Entretanto, nas descrições do Guia do Livro Didático, essa nova opção da editora Moderna se apresenta mais preocupada com a contextualização, a sintetização dos capítulos e a presença de elementos que vinculem a vivência do aluno com a Química (BRASIL, 2008; 2011).

Para a distribuição promovida em 2015, dado que tanto as obras de Feltre como de Canto e Peruzzo não faziam mais parte das coleções aprovadas pelo MEC, a preferência se transferiu novamente para aquela mais aproximada de uma sequência convencional de conteúdos, tendo assim os materiais de Martha Reis, 40,7\% das escolhas e a coleção Ser Protagonista, $30,9 \%$.

A estruturação dos dois LD apresentava uma forte base metodológica, preocupação em contextualização de conteúdos e interdisciplinaridade, vínculo com questões sociais, ambientais e tecnológicas, problematização de assuntos relacionados à vivência diária dos estudantes, entre outros aspectos que os tornam importantes e relevantes ao processo de seleção. Porém, ambos prezam por um desenvolvimento didático centralizado nos conteúdos da disciplina, logo, acabam por fortalecer o critério de escolha direcionado às obras de caráter convencional, justamente de forma a convergir para o que se pretende destacar neste artigo.

Visando aprofundar ainda mais a análise, no quadro a seguir será apresentada a estruturação dos capítulos desses seis LD, pretendendo demarcar a relação entre a sequência dos conteúdos e a abordagem didática das obras. Para isso, serão utilizados o sumário do volume 1 de cada material, que retrata a introdução da Química no Ensino Médio, possibilitando vislumbrar como cada autor ordena a sequência didática. 
Quadro 2 - Resumo de sumários dos volumes 1 nos LD utilizados no programa PNLD/EM de 2008 a 2015

\begin{tabular}{|c|c|}
\hline Referência & Sequência de conteúdos \\
\hline $\begin{array}{l}\text { FELTRE, R. } \\
\text { Química. 6. ed. São } \\
\text { Paulo: Moderna, } \\
\text { 2005. v. único. }\end{array}$ & $\begin{array}{l}\text { Capítulo } 1 \text { - Primeira visão da Química; Capítulo } 2 \text { - Conhecendo a matéria } \\
\text { e suas transformações; Capítulo } 3 \text { - Explicando a matéria e suas } \\
\text { transformações; Capítulo } 4 \text { - A evolução dos modelos atômicos; Capítulo } 5 \\
\text { - A classificação periódica dos elementos; Capítulo } 6 \text { - As ligações } \\
\text { químicas; Capítulo } 7 \text { - A geometria molecular; Capítulo } 8 \text { - Ácidos, bases e } \\
\text { sais inorgânicos; Capítulo } 9 \text { - Óxidos inorgânicos; Capítulo } 10 \text { - As reações } \\
\text { químicas; Capítulo } 11 \text { - Massa atômica e massa molecular; Capítulo } 12- \\
\text { Estudo dos gases; Capítulo } 13 \text { - Cálculo de fórmulas; Capítulo } 14 \text { - Cálculo } \\
\text { estequiométrico (BRASIL, 2008). }\end{array}$ \\
\hline $\begin{array}{l}\text { CANTO, E. L.; } \\
\text { PERUZZO, F. M. } \\
\text { Química na } \\
\text { abordagem do } \\
\text { cotidiano. } 4 \text {. ed. São } \\
\text { Paulo: Moderna, } \\
\text { 2006. v. 1, 2, 3. }\end{array}$ & $\begin{array}{l}\text { Capítulo } 1 \text { - Introdução ao estudo da Química; Capítulo } 2 \text { - Substâncias } \\
\text { químicas; Capítulo } 3 \text { - Introdução ao conceito de reação química; Capítulo } \\
4 \text { - Do macroscópico ao microscópico: átomos e moléculas; Capítulo } 5 \text { - } \\
\text { Introdução a estrutura atômica; Capítulo } 6 \text { - Noção mais detalhada da } \\
\text { estrutura atômica; Capítulo } 7 \text { - A tabela periódica dos elementos; Capítulo } 8 \\
\text { - Ligações químicas interatômicas; Capítulo } 9 \text { - Geometria molecular e } \\
\text { ligações químicas intermoleculares; Capítulo } 10 \text { - Condutividade elétrica de } \\
\text { soluções aquosas; Capítulo } 11 \text { - Princípios da química inorgânica; Capítulo } \\
12 \text { - Algumas reações inorgânicas de importância; Capítulo } 13 \text { - Mol; } \\
\text { Capítulo } 14 \text { - O comportamento físico dos gases; Capítulo } 15 \text { - Aspectos } \\
\text { quantitativos das reações químicas (BRASIL, 2011). }\end{array}$ \\
\hline $\begin{array}{l}\text { REIS, M. Química. } \\
\text { 1. ed. São Paulo: } \\
\text { Ática, 2013. v. 1, 2, } \\
\text { 3. }\end{array}$ & $\begin{array}{l}\text { Capítulo } 1 \text { - Grandezas Físicas; Capítulo } 2 \text { - Estados de agregação; } \\
\text { Capítulo } 3 \text { - Propriedades da matéria; Capítulo } 4 \text { - Misturas e substâncias; } \\
\text { Capítulo } 5 \text { - Separação de misturas; Capítulo } 6 \text { - Reações Químicas; } \\
\text { Capítulo } 7 \text { - Átomos e moléculas; Capítulo } 8 \text { - Notações Químicas; } \\
\text { Capítulo } 9 \text { - Alotropia; Capítulo } 10 \text { - Radioatividade; Capítulo } 11 \text { - } \\
\text { Modelos atômicos; Capítulo } 12 \text { - Modelo atômico básico; Capítulo } 13 \text { - } \\
\text { Tabela periódica; Capítulo } 14 \text { - Ligações Covalentes; Capítulo } 15 \text { - Forças } \\
\text { intermoleculares; Capítulo } 16 \text { - Compostos orgânicos; Capítulo 17 - } \\
\text { Compostos iônicos; Capítulo } 18 \text { - Compostos inorgânicos (BRASIL, 2014). }\end{array}$ \\
\hline $\begin{array}{l}\text { MORTIMER, E. F.; } \\
\text { MACHADO, A. H. } \\
\text { Química. 2. ed. São } \\
\text { Paulo: Scipione, } \\
\text { 2013. v. 1, 2, 3. }\end{array}$ & $\begin{array}{l}\text { Capítulo } 1 \text { - O que é Química?; Capítulo } 2 \text { - Introdução ao estudo das } \\
\text { propriedades específicas dos materiais; Capítulo } 3 \text { - Materiais: estudo de } \\
\text { processos de separação e purificação da água; Capítulo } 4 \text { - Aprendendo } \\
\text { sobre o lixo urbano; Capítulo } 5 \text { - Um modelo para os estados físicos dos } \\
\text { materiais: soluções sociais e sustentabilidade; Capítulo } 6 \text { - A história dos } \\
\text { modelos para o átomo e da tabela periódica; Capítulo } 7 \text { - Introdução às } \\
\text { transformações químicas; Capítulo } 8 \text { - Quantidades nas transformações } \\
\text { químicas; Capítulo } 9 \text { - Ligações químicas, interações intermoleculares e } \\
\text { propriedades dos materiais (BRASIL, 2014). }\end{array}$ \\
\hline $\begin{array}{l}\text { SANTOS, W. L. P.; } \\
\text { MÓL, G. S. } \\
\text { (Coords.). Química } \\
\text { Cidadã. 2. ed. São } \\
\text { Paulo: AJS, 2013. v. } \\
1,2,3 .\end{array}$ & $\begin{array}{l}\text { Unidade } 1 \text { - Consumo sustentável: Transformações e propriedades das } \\
\text { substâncias; Materiais e processos de separação; Constituintes das } \\
\text { substâncias; Química e Ciência; Unidade } 2-\text { Poluição atmosférica: Estudo } \\
\text { dos gases; Modelos atômicos; Unidade } 3 \text { - Agricultura: Classificação } \\
\text { periódica; Ligações químicas; Substâncias inorgânicas (BRASIL, 2014). }\end{array}$ \\
\hline $\begin{array}{l}\text { ANTUNES, M. T. } \\
\text { (Org). Ser } \\
\text { protagonista: } \\
\text { Química. 2. ed. São } \\
\text { Paulo: SM, 2013. v. } \\
1,2,3 \text {. }\end{array}$ & $\begin{array}{l}\text { Unidade } 1 \text { - Introdução ao estudo da Química; Unidade } 2 \text { - Propriedades } \\
\text { dos materiais; Unidade } 3 \text { - Do macro ao micro; Unidade } 4 \text { - Tabela } \\
\text { Periódica; Unidade } 5 \text { - Interações atômicas e moleculares; Unidade } 6 \text { - } \\
\text { Reações químicas; Unidade } 7 \text { - Funções da Química Inorgânica; Unidade } 8 \\
\text { - Contando átomos e moléculas; Unidade } 9 \text { - Estudo dos gases; Unidade } 10 \\
\text { - Estequiometria (BRASIL, 2014). }\end{array}$ \\
\hline
\end{tabular}

Fonte: Brasil (2008; 2011; 2014).

A composição dos sumários de cada material mostra que os livros dos autores Feltre, Canto e Peruzo, Reis e Antunes (Org.) possuem uma estrutura de conteúdos tida como 
convencional, pois listam e organizam os conteúdos da disciplina de forma análoga àquela esperada pela proposta curricular, enquanto Machado e Mortimer e Santos e Mól (Coords) mesclam essa razão com os aspectos sociais, culturais e ambientais, dando a impressão de que priorizam esses aspectos tanto quanto os conhecimentos científicos.

Vale destacar que as obras ofertadas na edição de 2015 do programa deveriam obrigatoriamente contemplar fatores socioculturais, e, portanto, é esperado que todas elas possuam capítulos ou descrições destinadas a estabelecer tais vínculos. Porém, infere-se que ao nomear cada capítulo com descrições convencionais do ensino de Química, ou se credita maior valor aos conteúdos científicos que as contextualizações socioculturais, ou, então, preza-se por manter um aspecto que favorece a continuidade da escolha, atraindo pela composição do sumário aquele docente que sempre opta pela estrutura mais aproximada da forma convencional de ensino.

Com isso, pode-se dizer que os LD com mais mudanças estruturais, a exemplo Mortimer e Machado ou Santos e Mól (Coords), acabam por ter menor adesão, pois deixam explícita a intenção da abordagem dos conteúdos, por um viés social, ambiental e tecnológico, não se importando em, por vezes, descontinuar a ordem de conteúdos adotada por autores de outros LD.

É importante também atentar para o fato de que o ensino de Ciências, tal como referenciado anteriormente, muitas vezes precisa se distanciar da dependência uníssona e do modelo delineado em alguns LD, adotando uma postura mais autônoma, contextualizada e condizente com o contexto escolar. Porém, para que isso se concretize, há a dependência de processos de formação docente que possibilitem promover novas compreensões acerca do ensino de Química e da seleção de materiais didáticos, pois é preciso promover uma ruptura com os padrões de ensino convencional se o desejo maior for o de formar cidadãos conscientes, críticos e participativos.

Isso pode se dar somente por meio de uma práxis em que situações históricas, tecnológicas e sociais estejam mais bem representadas nos conteúdos da disciplina, possibilitando que já no ambiente escolar, a liberdade de pensamento e a postura ativa possam ser praticadas (BRASIL, 2011).

\section{O padrão de escolha dos livros didáticos de Química sob a ótica fleckiana}

Ludwik Fleck foi um médico e epistemólogo judeu-polonês que dedicou boa parte de seus estudos à área bacteriológica, procurando auxiliar, por intermédio de análises sorológicas, o desenvolvimento do conhecimento acerca de algumas doenças do sangue. Em sua obra "Gênese e desenvolvimento de um fato científico", o autor procura contestar o neopositivismo defendido pelo Círculo de Viena para a época, por meio de explicações sobre 
a origem do conhecimento, exemplificadas por mediação de um fato científico muito presente em seu cotidiano de trabalho, o diagnóstico da Sífilis (LORENZETTI et al., 2011).

Com demarcações fundamentais sobre a ocorrência de um fato científico e a origem do conhecimento, Fleck descreve padrões de pensamento e comportamentos que poderão servir para auxiliar a compreensão dos porquês de os professores da rede pública de ensino apresentarem tamanha resistência a modificar as concepções acerca da escolha do LD.

A obra de Ludwik Fleck promove uma discussão sobre como uma "verdade científica" acontece e quais os fatores associados à sua formulação. Um dos aspectos que se destaca são as concepções adotadas e defendidas por indivíduos denominados especialistas, entendidos aqui como sendo aquelas pessoas que produzem o conhecimento científico, ou seja, os cientistas.

De acordo com Fleck (2010), ao se estabelecer um fato científico, provavelmente se tornará parte das concepções do referido especialista que o utilizará para explicar os diversos fenômenos por ele observados. Em outras palavras, ao se assumir certo corpo teórico explicativo (vários fatos), tem-se um Estilo de Pensamento (EP), logo, os sujeitos utilizarão esses referenciais (esse Estilo de Pensamento) para compreender e explicar o mundo que os cerca. Assim, de forma mais ou menos consciente, o EP determinará as escolhas que os sujeitos farão tanto no campo da ciência e, até mesmo, segundo Fleck, no seu cotidiano, implicando na forma de agir, pensar, falar e até mesmo vestir.

Com o desenvolver de novas experiências, observações e discussões, vinculados a certo EP, um indivíduo começa a tomar ciência sobre determinados assuntos, o que Fleck (2010, p. 136) descreve como sendo "o processo de conhecimento, [que] altera o sujeito do conhecimento, adaptando-o harmoniosamente ao objeto de conhecimento [...]", tornando-o com isso, especialista no tema ao qual observa e analisa (FLECK, 2010).

No entanto, um EP não é algo imutável, pois, ao se deparar com novos fatos que não possam ser explicados pelo corpo teórico em vigência, isso promoverá o que Fleck denominará de "Complicações" no EP, essas, por sua vez, levarão o especialista a buscar novos referenciais explicativos.

Nessa busca, para embasar determinadas hipóteses científicas pré-existentes ou idealizadas, há a formação de "acoplamentos" que irão fortalecer, refutar ou modificar as conjecturas de um ou vários especialistas, pois segundo Fleck (2010, p. 153),

[...] um fato é completamente independente de outros, mas se manifestam como um conjunto mais ou menos coeso [...]. Por isso, cada fato repercute retroativamente em outros e cada mudança, cada descoberta, exercem um efeito em um campo que na verdade não tem limites [...] cada fato novo altera todos os anteriores.

Contudo, cada alteração e reestruturação produzirá novos acoplamentos no EP, que, obrigatoriamente, formam 
[...] uma engrenagem universalmente coesa de fatos que se mantêm em equilíbrio mediante constantes efeitos recíprocos. Esse entrelaçamento interligado confere ao "mundo dos fatos" uma persistência maciça, causando a sensação de uma realidade fixa e da existência autônoma do mundo. (FLECK, 2010, p. 154).

Com isso, pode-se dizer que o EP funciona como um emaranhado de fatos, sendo denominada de "acoplamento" a ação de inserir novos fatos nessa esfera de conhecimento.

Tais acoplamentos poderão se caracterizar como passivos ou ativos, sendo o primeiro aquele em que os fatos não podem ser contestados, dando uma impressão irrevogável de veracidade associada a eles, acabando por tornar o especialista um agente passivo, não restando escolhas senão aceitá-lo e incorporá-lo em suas concepções, ao seu EP. Por outro lado, a forma ativa acontecerá quando, por sua vez, as constatações não expressarem grande persuasão (obrigatoriedade) sobre as concepções científicas, podendo o especialista optar se desejará ater-se a ele ou não. Deve-se destacar ainda que a força de coerção de um fato (podendo gerar acoplamentos ativos ou passivos) depende de quão abrangente é a comprovação de uma hipótese, ou até mesmo o quanto este novo fato é capaz de se associar às demais concepções presentes no pensamento do especialista (FLECK, 2010).

Outra referência importante com relação aos acoplamentos ativos e passivos é a sua relação com fatores científicos, sociais, históricos, políticos e econômicos. Por exemplo, quando um fato científico está amparado por outras teorias científicas, por fatores matemáticos e por concepções observáveis, existe uma ampla possibilidade de se tornar um acoplamento passivo, dada a sua verificabilidade e a dificuldade em contestar seus aspectos. Porém, deve-se ter em mente que, embora apresente tal dificuldade de contestação, não será tomado com incontestável ou como superior ao acoplamento ativo, uma vez que ambos são imprescindíveis para a construção do conhecimento.

De outra forma, os acoplamentos ativos estão intrinsecamente relacionados com fatores humanos, dado que cada indivíduo analisará e escolher de acordo com suas necessidades, crenças, disponibilidade financeira e períodos históricos se pretende incorporálo ao seu EP ou não. Assim, especialistas de uma mesma classe poderão destoar em alguns aspectos devido à existência desse tipo de acoplamento (FLECK, 2010).

Até aqui buscou-se promover um breve vislumbre sobre a formação do pensamento científico. Com isso, pode-se dizer que ele vai sofrendo acoplamentos ativos e passivos no decorrer das interações científicas que por ventura poderão ocorrer com o passar do tempo, moldando uma base sólida e persistente, capaz de receber mais e mais acoplamentos naquela essência primária. Vale acrescentar que, à medida que novos acoplamentos acontecem, o EP se consolida, tornando o especialista mais coercitivo e persistente em relação às suas ideias. Com isso, a mudança desse estilo e dessa forma de pensar é praticamente incompreensível e inimaginável (FLECK, 2010). 
A resistência do EP acontece de forma natural e dependente da estrutura de fatos que sustentam o conhecimento. Os diversos fatores associados à observação e à análise serão responsáveis por moldar uma barreira imaginária capaz de aglomerar todos aqueles que pensam de forma semelhante e separar os demais. Mas não é só a ciência que apresenta um caráter coercitivo, os “não-científicos” também. Pense, por exemplo, num mito transmitido de geração em geração, que ao formar um grupo de indivíduos crentes nas suas concepções, acaba por excluir todos aqueles que não são adeptos à ideia ou que tentam refutá-la. Então, de forma semelhante, quanto mais fatos estiverem associados a esse mito, mais difícil será de contrapor-se a ele, produzindo assim uma veracidade quase inquestionável a todos os participantes desse grupo, construindo com isso um pensamento persistente (FLECK, 2010).

Tomando agora uma perspectiva mais ampla, quando várias outras pessoas designadas especialistas, entendem como verdadeira (seja por meio de uma postura ativa ou passiva) aquela concepção postulada por outrem, que pertence ao seu grupo de especialidade, logo, ocorrerá um novo acoplamento nas concepções científicas, fazendo com que todos os participantes desse "grupo" norteiem seus pensamentos por uma mesma matriz, estabelecendo assim um coletivo para o determinado EP.

Sobre a gênese de um pensamento científico, conforme apresenta Fleck (2010), cabe detalhar alguns aspectos, como o Círculo de Ideias, que está aplicado no sentido de representar a base para o processamento do pensamento. Em suma, quando uma nova teoria científica chega ao especialista e adentra em seu "círculo" de ideias, lá ela será processada e comparada com as demais teorias existentes, passando por uma espécie de julgamento, cujo resultado final desse processamento será a refutação ou o acoplamento; essa ação converge diretamente à construção do EP que foi detalhado anteriormente.

Posto isso, espera-se uma associação de que esse tráfego de informações acontece por meio dos "Coletivos de Pensamento", os quais, para Fleck (2010) representa um grupo de circulação e harmonização de ideias, observações e objetivações ideologicamente semelhantes, nas quais cada sujeito desse coletivo é responsável por fundamentar e agregar valores, fazendo com que tais ideias, percepções e observações se construam e se solidifiquem.

Pode-se usar como exemplo um grupo de especialistas em Química Orgânica, em que todos os integrantes compartilham o mesmo tipo de conhecimento, acreditam de forma coesa nas leis fundamentais da Química Orgânica (acoplamentos passivos) e conversam rotineiramente para trocar ideias e discutir assuntos relacionados a essa área do conhecimento. Porém, deve-se considerar aqui que algumas experiências individuais (momento histórico, fatores sociais, fatores políticos ou econômicos), podem promover nesses especialistas alguns 
acoplamentos ativos, os quais irão modelar essas concepções de modo individualizado e com aspectos pessoais embutidos.

Embora todos esses químicos compartilhem uma mesma compreensão em relação à Química Orgânica, o foco de observação para cada especialista é particularizado. Isso faz com que o tráfego de informações entre eles aconteça sempre de modo construtivo e formador, carregado com concepções e pontos de vista próprios. No caso de haver uma constatação de um novo fato científico, ficará a cargo de cada especialista disponibilizar essa descoberta para o grupo e, dependendo do teor desse novo fato, após ele trafegar no círculo de ideias dos demais especialistas, durante o processo de aceitação, poderá sofrer novos acoplamentos (ativos ou passivos) até que seja integrado ao Coletivo de Pensamento (FLECK, 2010).

Enfim, para que seja possível estabelecer uma relação entre as concepções de Fleck e a escolha dos LD de Química, ainda se pretende delinear outros aspectos relacionados à prática docente. Em concordância com Tardif (2014), o processo de ensino-aprendizagem visto hoje nas escolas compreende, mesmo em ciências experimentais, uma ação memorística, a qual consiste em

[...] reduzir o saber, exclusiva ou principalmente, a processos mentais (representações, crenças, imagens, processamento de informações, esquemas, etc.) cujo suporte é a atividade cognitiva dos indivíduos. [Isso] parece ser a concepção de conhecimento predominante na educação, tanto em relação ao ensino quanto em relação à aprendizagem (TARDIF, 2014, p. 11).

Portanto, para esse tipo de visão, o saber ensinar está também associado aos processos sociais e históricos nos quais o professor está inserido. Em outras palavras, os docentes convivem com outros profissionais de uma mesma instituição, conversam sobre suas formações, partilham saberes, recursos, regras institucionais e resultados de práticas executadas em sala de aula e, no fim, constroem uma concepção particularizada de trabalho docente e de ensino-aprendizagem (TARDIF, 2014).

Porém, embora seja visto que o saber profissional vem sendo construído pela comunidade geral de professores ao longo da história, quando se pensa na prática docente, sua característica fundante (uma vez que os novos acoplamentos não eliminam concepções anteriores) é aquela constatada com mais frequência ao longo de todo o processo de ensinoaprendizagem, que marca o início, passada de geração em geração (TARDIF, 2014).

Por conseguinte, assim como descreve TARDIF (2014, p. 74) a visão convencional de ensino "[...] tem raízes na história anterior desses professores, [...] eles dizem ter aprendido através de aulas expositivas em que o professor apresentava a matéria [...]". Ou seja, trata-se de um discurso de legitimação, em que o profissional busca demonstrar o próprio aprendizado como um foco para validar sua concepção pedagógica. Dessa forma, se eu aprendi assim, como eles não conseguirão? Além disso, Tardif (2014) interliga o modelo de ensino adotado 
pelo professor - podendo ser convencional ou não - com aquele que os professores desse professor adotaram no decorrer de sua história.

Agora que já se discutiu, mesmo que de forma lacônica, como se constitui a prática docente, a opção metodológica de ensino convencional e a visão epistemológica da resistência de um estilo de pensamento, pode-se aproximar essas perspectivas da análise referente ao cenário de escolha das obras do PNLD/EM.

O principal aspecto que se percebeu com esse estudo foi a persistência no padrão de seleção das obras, tendo como possível reflexão para isso, a proximidade entre a estrutura dos LD e o Estilo de Pensamento dos professores. Faz-se essa associação com base na compreensão sobre acoplamentos ativos e passivos, produzidos pela constatação de fatos ao longo da vivência como estudante, da vida social, das crenças culturais e da formação e atuação profissional.

Em suma, quando se realiza um experimento, uma abordagem metodológica ou qualquer outra ação que exprima determinado sucesso, os acoplamentos começam a acontecer e fortalecer o EP, subsidiando o tráfego de informações dentro do Coletivo de Pensamento, provocando uma sensibilização e uma reformulação de concepções a partir de fatos, proposições e pré-ideias. Porém, conforme demonstra Fleck (2010), por mais que diversos acoplamentos aconteçam, a base de concepções sempre permanecerá sólida, exprimindo certo valor às demais convicções, sejam elas novas ou já existentes. Em razão disso, um docente formado de acordo com concepções convencionais de ensino, pode ser mais ou menos resistente às mudanças dessas concepções, tudo dependerá da gama de acoplamentos feitos ao longo de sua vida. Disso surgirá a necessidade por seguir o padrão na escolha dos livros didáticos (LORENZETTI et al., 2011).

Paralelo a isso, retomando a análise dos materiais didáticos, assim como apresentado no Quadro 1 e 2, percebe-se que os pareceres técnicos do livro didático de Machado e Mortimer e de Wildson Santos e Gerson Mól (Coords) descrevem uma estruturação diferenciada em relação aos demais, trazendo como características fundamentais os aspectos sociais, ambientais e tecnológicos, estimulando no ambiente escolar, a interdisciplinaridade, o diálogo e a reflexão, buscando por meio desses uma formação consciente do estudante.

Tais aspectos, embora muito favoráveis para a promoção de ACT, exigirão modificações (por meio de novos acoplamentos) no(s) EP que estejam vinculados os professores com concepções convencionais do ensino de Química, que, provavelmente, foram estabelecidas e fortalecidas ao longo do tempo (LORENZETTI et al., 2011). Em contrapartida, tem-se as obras que foram demarcadas com uma apresentação mais convencional, que embora se preocupem com a contextualização dos conteúdos, assumem 
uma característica exemplificadora, de onde se encontram os conteúdos formais de Química, atraindo aqueles profissionais que são resistentes à mudanças, ou, a novos acoplamentos.

Não se pretende classificar aqui os materiais quanto a níveis distintos de qualidade, mas demarcar que a estruturação de cada LD tende a conduzir as escolhas no PNLD, direcionando para as obras $\mathrm{x}$ ou $\mathrm{y}$, de acordo com as concepções pedagógicas e os EP dos professores de Química do Ensino Médio.

Porém, se a seleção do material didático deve ter como pressuposto o desenvolvimento da ACT dos estudantes, esperar-se-ia que a opção tivesse motivações mais amplas, como, por exemplo, as necessidades e realidades dos alunos. No entanto, a análise aqui desenvolvida indica que a preferência por certos materiais, na maioria das vezes, parece estar direcionada pelo EP ao qual o professor esteja vinculado, sendo esse, portanto, o motivo da prevalência pela escolha dos materiais próximos da concepção convencional de ensino de Química.

Ao se analisar a escolha dos LD e sua possível vinculação a uma concepção de ensino que, por sua vez, pode ser reflexo da presença de matizes mais intensos de um EP com características convencionais, tal como também identificou Lambach (2013), é preciso considerar que somente um LD de qualidade e que vise a ACT não assegura uma prática pedagógica que contenha atributos similares. Outros fatores também são determinantes, como as efetivas condições de trabalho em seus diversos âmbitos e, com significativo destaque, a formação docente de caráter permanente. Esta última, organizada com o propósito de promover a circulação intercoletiva de ideias, poderá estimular mudanças, mesmo que gradativas e a longo do tempo, em seus EP e, consequentemente, propiciar acoplamentos que favoreçam uma nova postura frente ao ato da escolha dos LD e ao exercício de uma prática pedagógica problematizadora e dialógica.

\section{Considerações finais}

Se o principal objetivo do PNLD/EM é subsidiar o acesso aos materiais didáticos, que devem ser periodicamente renovados para acordarem com as necessidades socioculturais de cada geração de estudantes, a escolha, por parte dos professores, demonstra nem sempre pactuar com esse objetivo.

A seleção das obras disponíveis parece ter dependência com as concepções, com as metodologias e com as histórias da formação docente e, a partir disso, é visto a existência de um padrão de escolha que está relacionado com o EP do Coletivo de professores de Química. Essa associação está sendo feita principalmente porque esse padrão mostra uma dependência com a estrutura dos conteúdos curriculares das obras, tendo o Coletivo, no decorrer dos anos, priorizado sempre aquelas com caráter convencional. 
Embora existam escolhas relacionadas aos materiais com caráter menos convencional (e isso pode se dar pelo fato de acoplamentos individuais levarem esses professores a pensar de forma diferente do coletivo), percebe-se que o grande grupo converge sempre a um aspecto semelhante, demonstrando resistência na mudança do EP, a qual foi fortalecida no decorrer dos anos e, agora, provoca persuasão e acoplamentos passivos até mesmo nos docentes que começaram há pouco tempo participar desse Coletivo.

Ao promover essa discussão, pretende-se colocar em evidência a necessidade de se levar em conta a existência de realidades distintas, para que essa consciência, em primeiro lugar, sirva como elemento orientador na hora de selecionar um LD distribuído pelo PNLD. Segundo Fleck (2010), o nosso olhar e ações são direcionados pelo nosso EP; porém, ao descrever a seleção como um processo consciente, espera-se fomentar a necessidade de não haver uma priorização do EP em detrimento das realidades e necessidades escolares.

Diante disso, a resposta para questão “qual obra escolher?" está além de um apontamento específico para determinado material, uma vez que todos os LD são validados por um comitê técnico, mas possuem estrutura particularizada de cada autor/editora. Portanto, na hora da escolha, é importante considerar as necessidades dos alunos, a promoção da ACT e a realidade de cada escola.

Desse modo, é preciso estimular ações de formação docente com concepções diferentes das que se realizam hoje. Tais ações devem explorar novos focos de discussão, pontos de vista, argumentos e referenciais teóricos, para que assim, seja possível promover perturbações nos EP e, com isso, possibilitar novos acoplamentos, ativos e/ou passivos, que permitam superar os padrões atuais de seleção dos LD.

\section{Referências}

BRASIL. Decreto n. 1.006, de 30 de dezembro de 1938. Coleção de Leis do Brasil. v. 4, 1938, p. 350. Disponível em: <http://www2.camara.leg.br/legin/fed/declei/19301939/decreto-lei-1006-30-dezembro-1938-350741-publicacaooriginal-1-pe.html>. Último acesso em: 28 ago. 2016.

BRASIL. Fundo Nacional de Desenvolvimento da Educação: Programa Nacional do Livro Didático (PNLD). Guia de Livros Didáticos: PNLEM 2008 - Química. Brasília: Ministério da Educação, Secretaria de Educação Básica, 2008.

BRASIL. Fundo Nacional de Desenvolvimento da Educação: Programa Nacional do Livro Didático (PNLD). Guia de Livros Didáticos: PNLD 2012 - Química. Brasília: Ministério da Educação, Secretaria de Educação Básica, 2011.

BRASIL. Fundo Nacional de Desenvolvimento da Educação: Programa Nacional do Livro Didático (PNLD). Guia de Livros Didáticos: PNLD 2015 - Química. Brasília: Ministério da Educação, Secretaria de Educação Básica, 2014. 
BRASIL. Fundo Nacional de Desenvolvimento da Educação: Programa Nacional do Livro Didático (PNLD). Disponível em: <http://www.fnde.gov.br/programas/livro-didatico >. Último acesso em: 15 fev. 2017.

CARVALHO, A. M. P.; SASSERON, L. H. Alfabetização científica: uma revisão bibliográfica. Investigação em Ensino de Ciências, v. 16, n. 1. p. 59-77, 2011.

FLECK, L. Gênese e desenvolvimento de um fato científico. Traduzido por Georg Otte e Mariana Camilo de Oliveira. Belo Horizonte: Fabrefactum, 2010.

FREIRE, P. Educação como prática da liberdade. 24. ed. Rio de Janeiro: Paz e Terra, 2000.

LAMBACH, M. Atuação e formação dos professores de química na EJA: Características dos Estilos de Pensamento - um olhar a partir de Fleck. Dissertação (Mestrado em Educação Científica e Tecnológica) - PPGECT. UFSC, Florianópolis, 2007.

LAMBACH, M. Formação Permanente de Professores de Química da EJA na Perspectiva Dialógico-Problematizadora Freireana. Tese (Doutorado em Educação Científica e Tecnológica) - PPGECT. UFSC, Florianópolis, 2013.

LORENZETTI, L. Alfabetização Científica no contexto das séries iniciais. 2000. 143 f.

Dissertação (Mestrado em Educação) - Universidade Federal de Santa Catarina,

Florianópolis, 2000.

LORENZETTI, L.; MUENCHEN, C.; SLONGO, I. I. P. As contribuições epistemológicas de Ludwik Fleck na produção acadêmica em Educação de Ciências. In: ENCONTRO

NACIONAL DE PESQUISA EM EDUCAÇÃO EM CIÊNCIAS, 8., 2011, Campinas. Anais... Campinas, 2011. Disponível em:

$<$ http://abrapecnet.org.br/atas_enpec/viiienpec/resumos/R1141-1.pdf>. Último acesso em: 13 jul. 2016.

NUÑEZ, I. B.; RAMALHO, B. L.; SILVA, I. K. P.; CAMPOS, A. P. N. A seleção dos livros didáticos: um saber necessário ao professor. O caso do Ensino de Ciências. Revista Iberoamericana de Educación (online), v. -, p. 1-12, 2003. Disponível em $<$ http://rieoei.org/did_mat1.htm>. Último acesso em: 13 mar. 2016.

TARDIF, M. Saberes docentes e formação profissional. Petrópolis-RJ: Vozes, 2014.

UNESCO. Ensino de Ciências: O Futuro em Risco. BR/2005/PI/H/13. Edições UNESCO, 2005. Disponível em: <http://unesdoc.unesco.org/images/0013/001399/139948por.pdf>. Último acesso em: 13 jul. 2016.

\section{SOBRE OS AUTORES}

TIAGO FRANCESCHINI DA ROSA. UTFPR - Universidade Federal Tecnológica do Paraná - Av. Sete de Setembro, 3165 - Bairro Rebouças - Curitiba - PR. Possui graduação de licenciatura em Química pela Universidade Paranaense (2008) e especialização em Ensino de Ciências pela Universidade Tecnológica Federal do Paraná (2014). Atualmente é Professor de Ensino Médio do Governo do Estado do Paraná e Professor Analista da rede de ensino Colégio SESI - Departamento Regional do Estado do Paraná. Tem experiência na área de Educação, com ênfase em Ensino de Ciências. Atualmente é mestrando do Programa de Pósgraduação em Formação Científica, Educacional e Tecnológica, pela Universidade Tecnológica Federal do Paraná (Campus de Curitiba). 
MARCELO LAMBACH. UTFPR - Universidade Federal Tecnológica do Paraná - Av. Sete de Setembro, 3165 - Bairro Rebouças - Curitiba - PR. Possui doutorado e mestrado em Educação Científica e Tecnológica pela Universidade Federal de Santa Catarina (PPGECTUFSC), especialização em TIC na Educação (PUC-RJ), especialização em Educação de Jovens e Adultos (UFPR), graduação em Química Licenciatura (UFPR) e graduação em Química Industrial (PUC-PR). Atualmente é docente Adjunto pela Universidade Tecnológica Federal do Paraná campus Curitiba (UTFPR) e docente permanente e Coordenador do Programa de Pós-Graduação em Formação Científica, Educacional e Tecnológica (PPGFCET). Editor da Revista ACTIO: Docência em Ciências desde 2016. Tem experiência na área de Química no Ensino Superior, Médio e Ciências do Ensino Fundamental, atuando principalmente nos seguintes temas: formação inicial e permanente de professores, educação científica, ensino na perspectiva de Paulo Freire, avaliação, educação de jovens e adultos (EJA), epistemologia, história e filosofia da ciência, tecnologias da informação e da comunicação (TIC), educação a distância, ensino de ciências e química com ênfase nas relações entre Ciência, Tecnologia e Sociedade (CTS).

Recebido: 10 de março de 2017.

Revisado: 17 de setembro de 2017.

Aceito: 12 de outubro de 2017. 